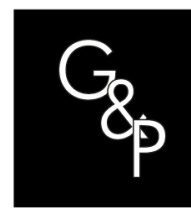

\title{
Maintenance, occupational health and safety: a systematic review of the literature
}

\author{
Manutenção, segurança e saúde no trabalho: uma revisão \\ sistemática de literatura
}

\author{
Marcelo Fabiano Costella ${ }^{1,2}$ (), Francieli Dalcanton ${ }^{1}$, Scheyla Maria Cardinal ${ }^{1}$, \\ Sandra Salete Vilbert ${ }^{1}$, Graciela Aparecida Pelegrini ${ }^{1}$ \\ ${ }^{1}$ Universidade Comunitária da Região de Chapecó - UNOCHAPECÓ, Programa de Pós-graduação em Tecnologia \\ e Gestão da Inovação, Chapecó, SC, Brasil. E-mail: costella@unochapeco.edu.br \\ ${ }^{2}$ Faculdade Meridional - IMED, Programa de Pós-graduação em Engenharia Civil, Passo Fundo, RS, Brasil.
}

How to cite: Costella, M. F., Dalcanton, F., Cardinal, S. M., Vilbert, S. S., \& Pelegrini, G. A. (2020).

Maintenance, occupational health and safety: a systematic review of the literature. Gestão \& Produção, 27(2), e3922. https://doi.org/10.1590/0104-530X3922-20

\begin{abstract}
The objective of this article is to use a systematic review of the literature to answer how the maintenance sector considers the occupational safety and health $(\mathrm{OSH})$ criteria, what impacts safety has on maintenance activities, which are the most significant branches of activities in this relationship, and which phases and types of maintenance are more prone to be influenced by $\mathrm{OSH}$. The articles for these studies were selected through the Capes Portal, limited to the period between 2010 to 2015. Articles selected from the Brazilian Congresses on Asset Management and Maintenance in the period from 2013 to 2015 were also used. 38 articles were selected in total for the systematic review of the literature. The results were summarized through conceptual maps and revealed that there are fundamental relationships between $\mathrm{OSH}$, Maintenance and Asset Management and that maintenance has a central role to play in these relationships. It is also concluded that the impacts of safety on the maintenance activities involve all stages of the process and that the maintenance sector considers the OSH criteria as a function of the safety of the persons performing the maintenance and operating the equipment. The contributions include a discussion on the importance of maintenance and safety according to different organizational cultures, the elements considered in management practices, maintenance strategies and safety criteria.
\end{abstract}

Keywords: Maintenance; Occupational health and safety; Asset management; Risk management; Systematic literature review.

Resumo: O objetivo deste artigo é responder, através de uma revisão sistemática de literatura, como o setor de manutenção considera os critérios de segurança e saúde no trabalho (SST), quais os impactos da segurança nas atividades de manutenção, quais os ramos de atividades mais significativos nessa relação e quais fases e tipos de manutenção estão mais propensas a sofrer influências de SST. Os artigos para esta pesquisa foram selecionados através do Portal Capes, limitando o período entre 2010 a 2015. Também foram utilizados artigos selecionados dos Congressos Brasileiro de Manutenção de Gestão de Ativos no período de 2013 a 2015. No total foram selecionados 38 artigos para a revisão sistemática de literatura. Os resultados foram sumarizados por meio de mapas conceituais e indicaram que existem relações intrínsecas entre SST, Manutenção e Gestão de Ativos e que a manutenção tem um papel

Received Apr. 3, 2017 - Accepted Dec. 17, 2018

Financial support: None.

This is an Open Access article distributed under the terms of the Creative Commons Attribution License, which permits unrestricted use, distribution, and reproduction in any medium, provided the original work is properly cited. 
central nestas relações. Também concluiu-se que o impacto nas atividades de manutenção na segurança compreendem todas as fases do processo e que o setor de manutenção considera os critérios de SST em função da segurança para quem realiza a manutenção e para quem opera os equipamentos. Como contribuições, discutiu-se a importância da manutenção e segurança segundo culturas organizacionais diferentes, elementos considerados nas práticas de gerenciamento, estratégias de manutenção e critérios de segurança.

Palavras-chave: Manutenção; Segurança e Saúde no Trabalho; Gestão de Ativos; Gerenciamento de Risco; Revisão sistemática da literatura.

\section{Introduction}

The importance of the maintenance sector in organizations concerning the other sectors has evolved with the passing of the years from a simple support area to a strategic support area (Santos \& Martins, 2015). Many still see the professionals working in this sector as the ones who address $90 \%$ of daily maintenance problems. However, considering the current technological developments, a person or even a group of people would rarely solve the majority of cases that could occur within an industry. The maintenance branch has therefore sought new ways of thinking, both in the technical and administrative area, since these new market requirements have brought the limitations of the current systems to light (Bristot et al., 2012). Consequently, it is natural that the safety of these activities has become increasingly complex.

Xenos (2004) conceives maintenance as being a set of technical and administrative actions intended to maintain an item or system in a state in which it can perform the functions for which it was designed. Rosqvist et al. (2009) refers to maintenance as a combination of all the technical, administrative and management actions during the life cycle of an item, which are meant to maintain the state and safety of said item, or to restore it to a state in which it can perform the desired function (Grusenmeyer, 2014). The strategic importance is linked to the capacity to ensure the availability of equipment and installations with reliability, safety and appropriate costs (Xavier, 2013; Mosquim, 2015).

Maintenance can be classified into the following types: corrective, proactive, preventive and predictive. Corrective maintenance consists in an intervention made after the occurrence of the failure. Proactive maintenance is performed prior to failure, being subdivided in preventive maintenance, which is characterized as the service performed on equipment that has not presented failures, but of which one nevertheless knows the useful life of components, with their exchange being scheduled prior to the estimated conclusion of this cycle, and predictive maintenance, which allows you to optimize the exchange of parts or the renovation of components and to extend the range of maintenance, since it uses testing to predict when a part or component is near its life cycle limit (Silva et al., 2015).

According to Lafraia (2011) and Barbosa (2015), maintenance is assessed in conjunction with workplace safety in risk management. The good maintenance and safety practices of a company should serve as the foundation for risk management, making decisions more assertive for a project or implementation process.

Safety is a priority in the whole maintenance system and should be part of the routine procedures. It elevates the level of complexity of the planning and implementation activities, establishes limits and ideal work conditions, and imposes 
higher levels or new targets for planning. Protective systems geared to the reduction or elimination of hazards are usually considered to increase safety levels (Marais et al., 2004).

Asset Management emerges in this context. It brings a new paradigm to the field of maintenance (Santos \& Martins, 2015). The NBR ISO 55000 standard stresses that effective control of assets involves risk management, with as main objective achieving an optimum balance between cost, risk and performance. Asset management enables organizations to achieve their long-term goals in a sustainable manner (ABNT, 2014).

Finally, there is an effort to increase the reliability of production systems so that they deliver the products demanded by their customers at the right time. Reliability in engineering is defined as the probability that a component meets specified requirements under certain conditions over time. Within maintenance, it is a concept used to define maintenance intervals and the performance levels of equipment. Safe systems are not necessarily reliable and vice versa. In fact, these two qualities are often in conflict (Marais et al., 2004).

The objective of this study is to use a systematic review of the literature to check how the selected articles cover the influence of occupational health and safety on maintenance and how they consider the asset management concept in order to answer four relevant research questions.

\section{Research method}

\subsection{Research questions}

This study can be classified as an exploratory study in terms of research methodology and, as such, the definition of the research question should consider the required scope.

Starting with the proposition that there is an interaction between the concepts of maintenance and occupational safety and health $(\mathrm{OSH})$, the following research question was defined: "What are the relationships, impacts and existing interactions between the maintenance, asset management and occupational health and safety activities?"

Three questions about the interaction between maintenance and $\mathrm{OSH}$ and a subsequent question to detail the maintenance activities, life cycle and type covered by this interaction were posed to answer this research question and to systematize the article in order to discuss how the researchers have discussed these aspects. The questions are listed below:

a) What is the relationship between asset management, maintenance and $\mathrm{OSH}$ ?

b) What is the impact of occupational safety on maintenance activities?

c) How does the maintenance sector consider the OSH criteria?

d) What are the most impactful branches of activity in the maintenance literature that consider OSH? Which phases (design, implementation, review) and types of maintenance (preventive, corrective and predictive) are more prone to suffer influences from $\mathrm{OSH}$ ? 


\subsection{Search strategy}

This study is characterized as a systematic review of the literature on maintenance and its influence on occupational safety and health $(\mathrm{OSH})$. Some criteria were considered for the selection of the articles of this review, which sought to cover articles in national and international journals in the Capes Portal, in addition to articles with national applied research taken from the Brazilian National Congresses on Maintenance and Asset Management held by the Brazilian Association of Maintenance and Asset Management (ABRAMAN).

The following databases were selected in the Capes Portal for the search: Materials Science \& Engineering Database, OneFile (GALE), Science Direct Journals (Elsevier), Taylor \& Francis Online - Journals e ProQuest Advanced Technologies \& Aerospace Collection. The selection included only articles published in peer-reviewed journals between 2010 and 2015 in the Portuguese or English language.

After a preliminary study step of the search engines with iterations of different terms and combinations, those keywords were chosen which allowed for the selection of articles that could answer the proposed research questions. The answers to two combinations of keywords were considered in the search tool: maintenance, safety and "risk assessment" or "risk management", which returned 41 results and the words "maintenance and accident prevention", with 167 results, totaling 208 articles.

The study of the articles published in the Brazilian Congresses on Maintenance and Asset Management was limited to the last three editions of the Congress, i.e., the 28th edition of 2013, the 29th edition of 2014 and the 30th edition of 2015. Two keyword combinations were used for this article selection: "Manutenção" and "Gestão de Riscos" or "Avaliação de Riscos", which yielded 338 results, and the words "manutenção e segurança e saúde no trabalho" with 171 results, totaling 509 articles.

The criteria for the exclusion/inclusion of articles were meant to enable screening of relevant articles on maintenance management with a focus on occupational health and safety. The exclusion criteria were repeated articles and the abstract's and content's lack of adherence and potential to answer at least one of the four selected research questions. In the case of the articles published in the Brazilian Congresses on Maintenance and Asset Management, the focus was also on the presentation of the application results of the case studies.

Eighteen articles were selected from the Capes Portal after reading the titles and abstracts. Two articles were excluded after reading, leaving a selection of 16 articles in total. 57 articles of the Brazilian Congresses om Maintenance and Asset Management were selected after reading the titles and abstracts and, after reading the full text, 8 articles were selected. At this point, the study counted with 24 selected articles.

In view of the main objective of answering the broad research questions, complementation of the references proved necessary through the implementation of "snowball" sampling. This consisted of a search for other relevant works which were not returned by the selected keywords based on the references of the articles selected for analysis. 14 articles were included in this second reading phase, even if they were publications prior to 2010.

Thus, a total of 38 articles were selected, according to the summary presented in Figure 1. 


\section{Search Start}
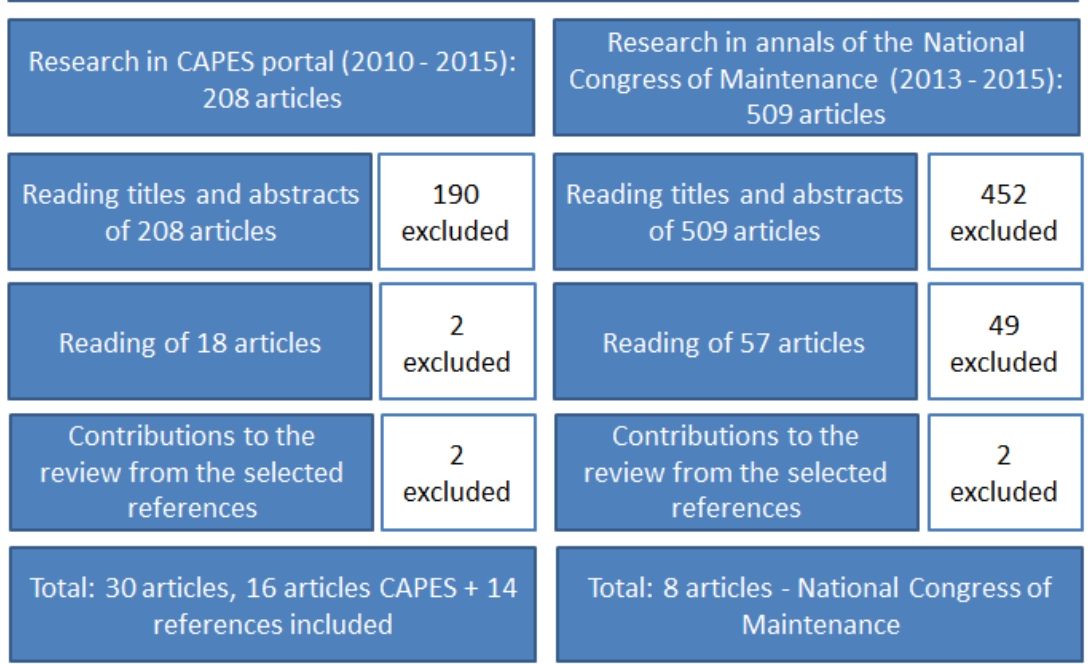

Figure 1. Selection of the articles for a systematic review of the literature. Source: Developed by the authors.

\subsection{Summary and presentation of the results}

After the search and coding of the articles, the presentation of the results was organized in such a way as to answer each of the research questions. In addition, conceptual maps were constructed throughout the results and discussion to assist in the understanding of the aspects under study.

\section{Results and discussion}

\subsection{What are the Relationships between Asset Management, Maintenance and Occupational Safety and Health (OSH)?}

The ABNT NBR ISO 55000 standard establishes that the main objective of an effective control of assets is to pursue an optimum balance between cost, risk and performance (Santos \& Martins, 2015). Since the maintenance and safety activities interfere with this balance, they need to be controlled through systematic and coordinated activities.

Maintenance is a complex system involving multiple activities, from management and planning to the implementation and review of procedures. Its complexity is attributed both to the emergence of new requirements, such as energy efficiency, safety and social impact, but also to new information and communication technologies (lung et al., 2009). In this context, maintenance gains a much larger objective than just repairing; it proposes to maintain the standards of efficiency, safety and technology that ensure the stability of the company's activities.

Mather (2005) cites six elements that must be taken into consideration in maintenance management practices: productivity, profitability, safety, learning, quality and environmental concerns. In order to meet these requirements, maintenance 
activities become intrinsically integrated with the management of human resources, safety, quality and production, bringing about the first relationship between occupational health and safety and maintenance: integrated management.

One approach in safety risk assessment involves the division of the types of causes: the reactive safety indicators, which have already been analyzed on a large scale in the literature; and the influencers, also known as proactive indicators, which must be increasingly observed in the process).

Another angle of analysis is to look at the objective of each activity. OSH focuses on the worker in his work environment, seeking to mitigate accidents, occupational diseases, protecting the worker's integrity and his ability to perform the work. The main $\mathrm{OSH}$ target is the human being, while maintenance broadly pursues to observe equipment, workers and the environment, but with equipment as the main target.

Management often seeks solutions to remedy safety and maintenance problems. This occurs visibly when there is the elimination of a risk by replacing a piece of equipment or component that causes danger by another which uses the best technology or less harmful chemical agents. Other times, the solution of one problem will result in secondary demands to be resolved by the other field. Dual protection systems, for example, generally require a higher level of maintenance, incurring higher costs.

Maintenance influences the health and safety of workers in two ways: firstly, properly planned and executed maintenance is essential to maintain the work system and environment safe and reliable. This way, maintenance will contribute to the elimination of dangers in the workplace. No maintenance action or actions in general should lead to dangerous situations, accidents and health problems. Secondly, maintenance should be performed safely, with the adequate protection of maintenance workers and other people present at the place of work, because this is a high-risk activity (Blaise et al., 2014).

Grusenmeyer (2014) points out that maintenance was associated with 10 to $15 \%$ of fatal industrial accidents and 15 to $20 \%$ of all accidents in Europe in 2006. The author points out that the relationship between maintenance and safety is contradictory. Maintenance contributes to a reduction in risk through the prevention and correction of non-ideal modes of operation of equipment, while also causing accidents if one considers that maintenance activities naturally expose maintenance workers to risk.

Risk can be considered in several ways, as variability of yields, a probability of catastrophic events or as a classification derived from legislation. In Asset Management, risk tends to reflect safety and environmental damage issues (Mather, 2005). In Maintenance, risk can be reflected in safety factors in maintenance activities identified as critical, both for the safety of the operator and for the safety and reliability of systems. Maintenance should be considered as a potential source of risk to the operators involved in maintenance, in the case of maintenance failures, and also as a potential source of risk to other people and of serious accidents (Grusenmeyer, 2014). These concepts set Asset Management apart, emphasizing the focus on the company's assets, seeking to control performance, risk and cost in a more comprehensive way than maintenance.

Murphy (2010) mentions that organizations focus on three main elements: asset safety, reliability and performance (availability, utilization and cost minimization). These elements are directly linked to the financial performance of organizations and 
can be perceived almost immediately when they are influenced. In this context, maintenance can be considered as the main system that enables sustaining a physical item, whether it is a place of work, a piece of equipment or a means of transport, in a state in which it can perform the desired function (Blaise et al., 2014). This is seen as a tool to hit such targets as reliability and availability, while also playing a role in minimizing costs.

Narasimhan et al. (2010) tried to determine the level of maintenance routines and risk factors for accidents in mechanized farms and showed that the most modern technological equipment require less maintenance hours. This corroborates the asset management assessment model by considering technologies, the useful life of equipment and their maintenance within the administrative tools.

Considering the above, it should be noted that, for management, maintenance has a direct relationship with asset management and $\mathrm{OSH}$ with management activities in general, seeking the same objective and with each one even having practices designed to service the other field. For example, maintenance geared toward safety and performance and $\mathrm{OSH}$ risk assessment for maintenance and maintenance for the reliability of asset management.

Reason \& Hobbs (2003) discussed safety culture and admit that, for some organizations, the consequences of failure in asset management are so important that the safety issues should be of equal importance as profit. Murphy cites the examples of failures in airlines, petrochemical plants and nuclear power plants (2010).

According to Bourrier (1996), different elements can contribute to establish if maintenance activities are critical for the safety of the operator and the nature of the maintenance activities, the conditions in which the maintenance activities are performed and the organization of the maintenance, inside and outside the company, should also be evaluated. As can be seen in Figure 2, these arguments reveal that cultures focused on safety and reliability establish an important relationship between asset management, maintenance and safety, while those focused on performance still see safety as a cost to be taken into consideration within companies.

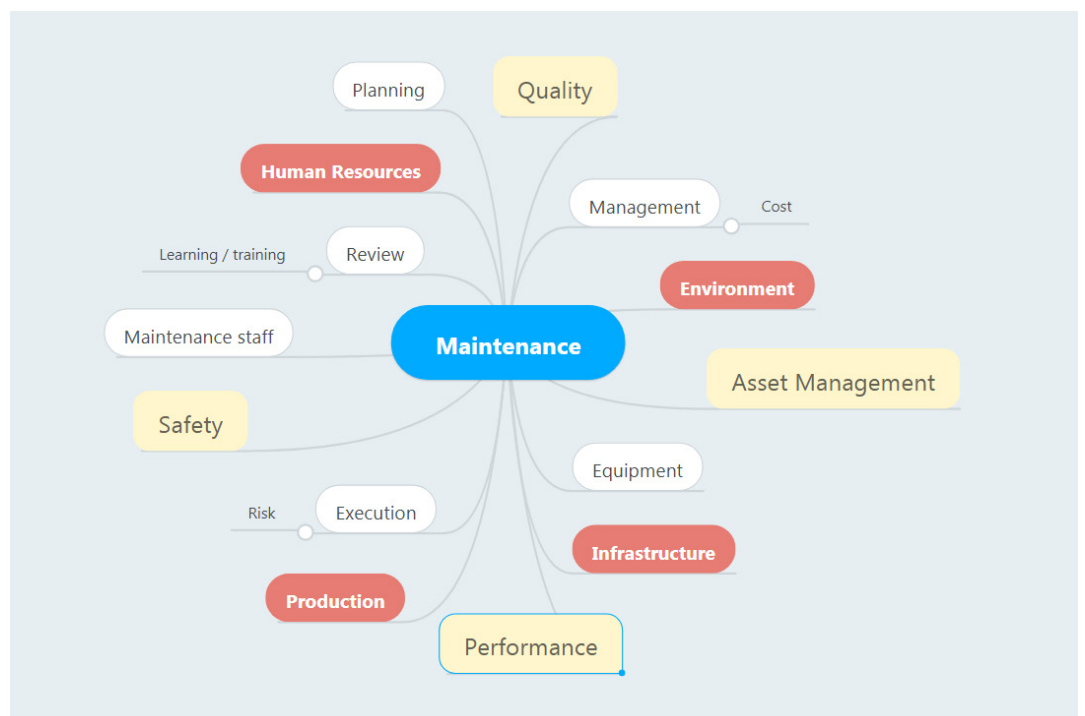

Figure 2. Interactions of the Maintenance function in the company Source: developed by the authors. 
Zhao et al. (2000) classify maintenance activities as online and offline. The on-line activities comprise the inspection to determine the status of the equipment or system, the evaluation (to find out what the problem is), the decision-making on maintenance (strategies and priorities) and taking action (lubricate, repair, replace, etc.). Offline maintenance, on the other hand, considers the activities performed during the shutdown of the plant, when maintenance work is performed during the shutdown of the system as a whole. It can also be classified into four main stages of operation: 1 - Identifying the maintenance requirement; 2 - Preparatory work stages; 3 - Development and action; and 4 - Restoration of normal conditions. It is extremely important for anyone working with safety within maintenance to understand these classifications, since there are levels of risks associated to each activity, whether it is an inspection, a maintenance service or a plant shutdown. In the same way, it is essential that the safety issues and institutional cost - both related to asset management - are taken into account in the decision making and priority setting. Figure 3 presents a summary of these classifications.

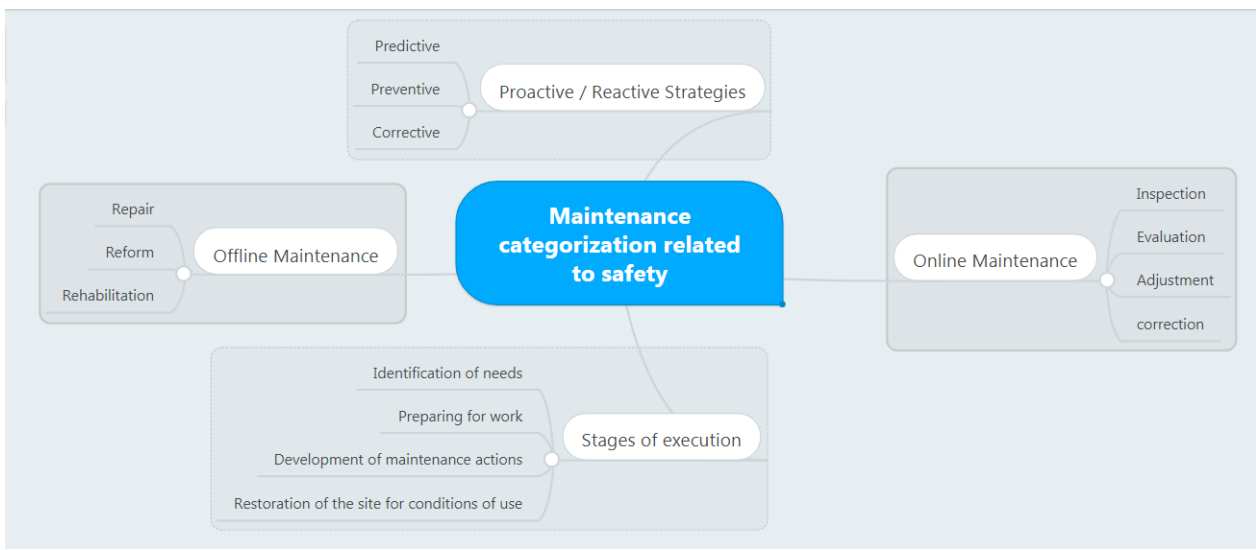

Figure 3. Maintenance classifications while evaluating safety issues. Source: developed by the authors.

According to Blaise et al. (2014) corrective and proactive strategies (preventative and predictive) have been developed to restore an equipment or system from a failed state, reduce the probability of failure or even to minimize the deterioration of the functioning of an equipment or system. The first case is representative of the corrective maintenance strategy, while the second is linked to the preventive strategy. $\mathrm{Hu}$ \& Zhang (2014) reported that the corrective maintenance time is usually unexpected, while that preventive maintenance is planned. Many times, small repairs are carried out on the components so the state can be maintained until the preventive maintenance interval arrives.

The choice between different maintenance strategies has a direct impact on the costs of the company's operation and within asset management that considers the level of their planning and resources. It is essential to know the cost of shutting down a piece of equipment during production, which leads to the idleness of employees and loss of production. Costs related to $\mathrm{OSH}$ also vary depending on the strategy, exposing employees to risk in case of equipment failure during production, with leakage of toxic substances, extreme temperatures or even contact with mechanical parts that generate accidents. 
In a context of engineering assets, reliability is defined as the probability that a component meets its specific behavioral needs over time and under certain conditions (Marais et al., 2004). The importance of reliability of engineering assets is evident when examined against their contribution to other asset management performance metrics, such as availability and utilization. Asset management has another dimension related to reliability, however, evaluating the consequences of failures, involving both financial and safety issues (Murphy, 2010).

Repair and maintenance based on maintenance time or based on detection can be used to temporarily repair the parts without eliminating the root cause. In practice, these activities are generally imperfect and cannot restore the system so that it is as good as new (Hu \& Zhang, 2014). The planning and control of activities is therefore considered as a link to follow up on the solution of these root problems, when managerial activities are added to the practices so failures do not reoccur. This increases safety in the company as a whole, including for employees, since they are exposed to less risk because there is no recurrence and because the safety of these pieces of equipment is often improved following these solutions.

In order to develop a generic model, Herrera et al. (2009) state that, in order to evaluate safety in maintenance activities, it would be necessary to take the experience of different industries into account and present a maintenance management model that consists of three levels: policies; planning and procedures; and implementation and feedback.

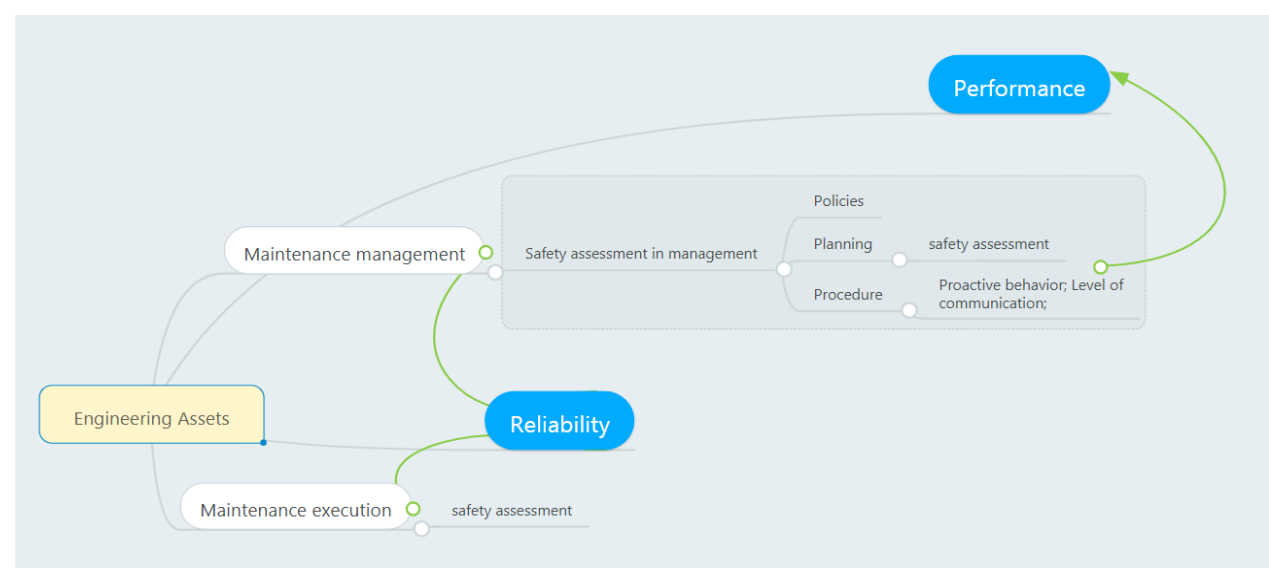

Figure 4. Paths to performance and reliability. Source: developed by the authors.

Organizational cultures that ensure reliability and performance have incorporated the management of $\mathrm{OSH}$ issues into their criteria more easily. For example, the practice of giving value to employee awareness, favoring proactive behavior, high levels of interpersonal and intra-organizational communication, a mindset that appreciates prevention-driven initiatives (Bamber et al., 1999; Weick et al., 2008). Both emphasize the importance of leveraging the knowledge and experience of the engineering work force to ensure the continuous improvement of processes for the prevention of accidents and to improve the capability to respond locally and quickly when needed (Murphy, 2010). Figure 4 represents these arguments. 


\subsection{What is the impact of occupational safety on maintenance activities?}

Safety interferes with the managerial and operational maintenance activities, because when the planning is done, one has to know the risks and the conditions in which they should be performed, demanding knowledge on safety from the planning team.

Considering that maintenance currently has a broader role (Al-Shanini et al., 2014), the use of auxiliary tools as hazard identification, prevention and prediction systems tends to provide information that can be effectively used in risk-based decisions to prioritize maintenance plans, manage change and suggest the need for new safety measures in both operations and maintenance. A maintenance schedule can therefore have its activities changed as a function of safety issues and still make strategic use of opportunistic actions during maintenance to remedy issues raised in safety assessments by including them in the maintenance shutdowns, which would have an influence from planning until completion.

When considering the high levels of planning in maintenance, where there is a systematization of activities and an assessment of root causes of accidents during the repair activity or even those caused by improper maintenance activities, there is a realization that the majority of individual failures usually have multiple paths of propagation. Any small local deviation, therefore, could be amplified, resulting in a serious accidents and leading to economic losses. In many cases, especially in the energy industries where the safety aspect is important, the impact of an accident caused by a failure is often very sensitive and significant in relation to the maintenance cost (Hu \& Zhang, 2014).

In the case of maintenance in high-tech industries, Chen et al. (2014) describe a reduction in accidents with improvements in maintenance planning, including the maintenance of safety equipment from the factory, the adjustment and improvement of safety systems carried out during the annual maintenance shutdown and the inclusion of personal protection equipment for online maintenance activities.

Observing the operational part, the causes of accidents during maintenance are usually grouped into active errors and latent conditions, such as human actions, technical and structural workplace factors and organizational factors like administration and supervision. Most of the time, therefore, organizational, technical and human resources are regarded as the three main categories of accident maintenance (Blaise et al., 2014). As such, the influence of OSH on maintenance is to preserve safety by encouraging the use of personal protection equipment and performing technical trainings that include safety and the supervision of activities with safety in mind, which can be done through internal monitoring or audits.

The risk assessment model used in the study by Herrera et al. (2009) indicates the levels of maintenance and the essential elements that should be taken into account to assess safety management. These elements include policy, corrective and preventive maintenance, modifications, maintenance tasks, engineering orders, inspection programs, maintenance work scheduling, planning and execution, reporting and analyses.

As such, maintenance also needs to involve knowledge of safety in all its activities, just as $\mathrm{OSH}$ needs to take factors into account that arise when evaluating the maintenance structure, which leads many companies merge common activities. In order to ensure the safety of operations of hydroelectric power plants, for example, maintenance and supervision programs are cited as items to be included in the safety and health management plans, generating integrated maintenance and safety models (Saedi et al., 2014). 


\subsection{How does the maintenance sector consider the osh criteria for the company and for the maintenance operator?}

Preserving and improving working conditions in a company, considering the material part of equipment and facilities, is the responsibility of maintenance. The maintenance of the installed safety systems; the temperature, humidity, lighting and ventilation conditions; the equipment use conditions; the entire structure making up the work environment; these factors require maintenance to comply with safety legislation and standards to prevent accidents as a result of poor conditions to which workers could be exposed. It is therefore important that the maintenance is planned and executed so as to avoid the risk of deterioration.

Most companies, depending on their area of activity, require interruptions in their activities, whether these occur daily, weekly or yearly. When an error or failure occurs in a particular component that could cause the collapse of the system, the entire system generally needs to be turned off for corrective maintenance. Using maintenance strategies, the planned interruption should be performed to carry out repairs, replacements and improvements when the preset service interval arrives. Although both types of maintenance strategies require a shutdown of the system and involve costs related to downtime and maintenance, these are generally less severe than situations where the system breaks down, which can lead to serious accidents, environmental pollution and even greater delays to restore the system (Hu \& Zhang, 2014). Still keeping these strategies in mind, it is very important to consider safety criteria in the planning of the maintenance intervals because this can also cause accidents if performed incorrectly, inadequately, excessively or too late (Okoh \& Haugen, 2013).

The study by Hu \& Zhang (2014) emphasizes that an optimal maintenance policy must take the combination between the various parameters of maintenance operations into account, such as the position of the components that need repair, losses due to downtime, minimum repair costs, costs of preventive and corrective maintenance and the risk of failure. The latter involves the safety concept, since when risk is assessed the consequences for people and the environment are considered.

The impact of an accident caused by a failure is very sensitive and significant when compared with the cost of maintenance (Hu \& Zhang, 2014).

The safety of people working in companies depends on maintenance, on good work conditions, especially when one analyzes those that might cause problems involving toxic gas leaks, electrical insulation failures or mechanical failures that endanger the safety of anyone operating the equipment.

Considering the operational maintenance levels, there are safety criteria to be considered in various approaches:

(a) The annual maintenance time for major petrochemical plants, the sudden workload, the numerous interruptions and the growing demand for more workers requires contractors to employ temporary workers (Zhang \& Zheng, 2012). These workers are often unaware of the potential risks in these environments, which requires the implementation of trainings even before the activities begin (Cheng et al., 2013);

(b) The conditions of the deployment operation can also affect the health and safety of the worker. Many times, they are working at night or early in the morning, in confined spaces, on raised platforms, and in a variety of conditions of humidity 
and inadequate lighting. The work can be physically exhausting and require attention to detail (Blaise et al., 2014);

(c) Planning the activities considering the safety criteria and overseeing the implementation of the activities regarding the compliance with protective measures incorporated in the planning, such as a power isolation, correct use of tools and individual protection equipment (Grusenmeyer, 2014);

(d) The interaction between production and maintenance, the contribution of both on a same component, the mutual dependency. For safety reasons, maintenance may mean stopping a production process when maintenance cannot occur online or it may even require workers to operate in hazardous locations (Zhao et al., 2000);

(e) The transfer of some maintenance operation to production in order to support a philosophy like TPM (Total Productive Maintenance).

Maintenance operations can be fully or partially outsourced or subcontracted. Maintenance performed by a contractor has to be integrated into the ongoing activities of the company to ensure the health and safety of all workers involved (Blaise et al., 2014).

Figure 5 shows the impact of these planning activities on maintenance.

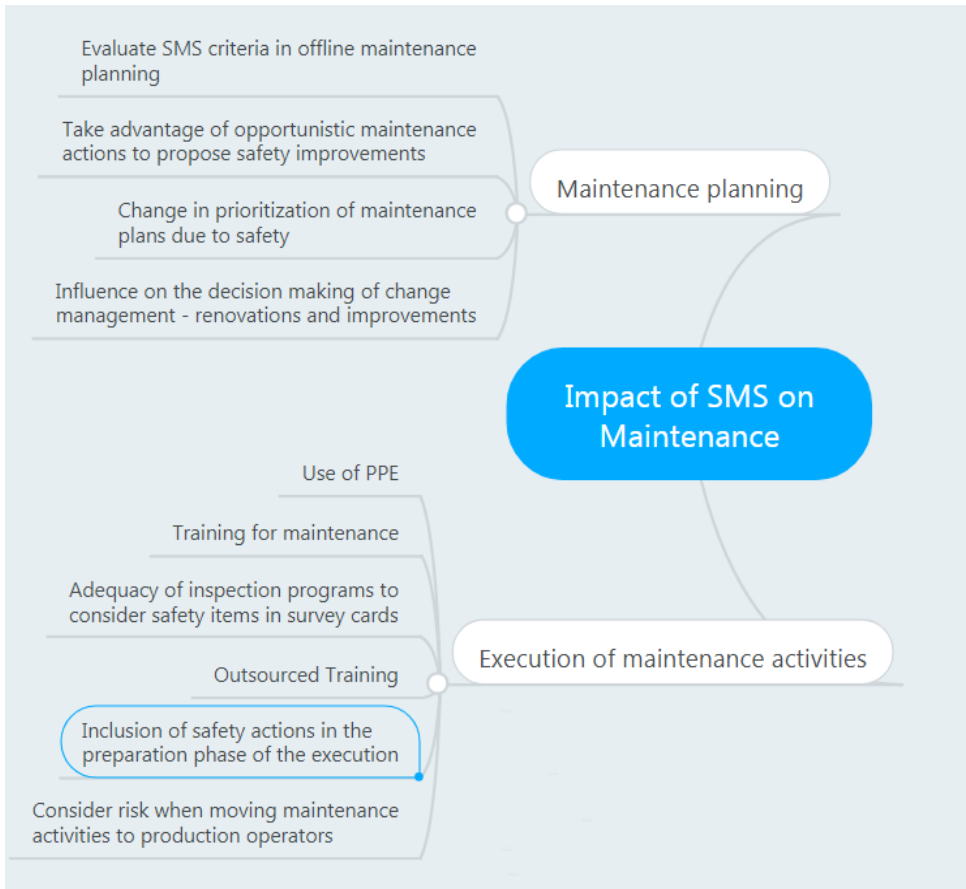

Figure 5. Impact of OSH on Maintenance. Source: developed by the authors.

\subsection{What are the most impactful branches of activity in the maintenance literature that consider OSH?}

In 1998, the American Petroleum Institute (API) studied 100 serious accidents in the oil industry over the last 30 years and its causes, discovering that mechanical failure was responsible for $44 \%$ of these accidents. However, they discovered that 
during regular maintenance or inspection, workers often performed unsafe actions, ignored the safety and protection devices or ceased to use them properly, with the study pointing to maintenance as a cause of $73 \%$ of accidents. Furthermore, $51 \%$ of accidents resulted from moving or compression actions of equipment to perform cleaning, lubrication, adjustments or repairs, with the individual not following the proper procedures during the action (Cheng et al., 2013).

The International Air Transport Association (IATA) showed that maintenance events contributed to approximately $20 \%$ of all global accidents for the year 2007 (Rashid et al., 2014).

In the energy segment, petrochemical, hydroelectric and hydrogen power plants use complex safety assessments in their facilities (Al-Shanini et al., 2014). The same occurs in various public and private bodies, for example the navy, rail services, aviation and department of transport classify their serious accidents related to maintenance, which are preceded by latent conditions, threats, errors and undesired maintenance (Okoh \& Haugen, 2013).

Hobbs (2000) reported that maintenance errors contribute to $12 \%$ of accidents with airline aircraft and that $50 \%$ of flight delays are related to problems presented by engines. A study conducted by Holloway \& Johnson (2004) between 1996 and 2003 in the United States indicated that management issues contribute to $17 \%$ and the regulatory failures to $12 \%$ of probable causes of aviation accidents. Inadequate maintenance and inspection can be considered as the second biggest safety threat (Hobbs, 2004).

A study conducted by Narasimhan et al. (2010) found that in the year 2006, 11 of the total of 159 accidents in farms in the province of Saskatchewan, Canada, were related with the maintenance of agricultural machines.

Figure 6 represents a summary of the sectors that contribute most to the generation of knowledge in the field of maintenance.

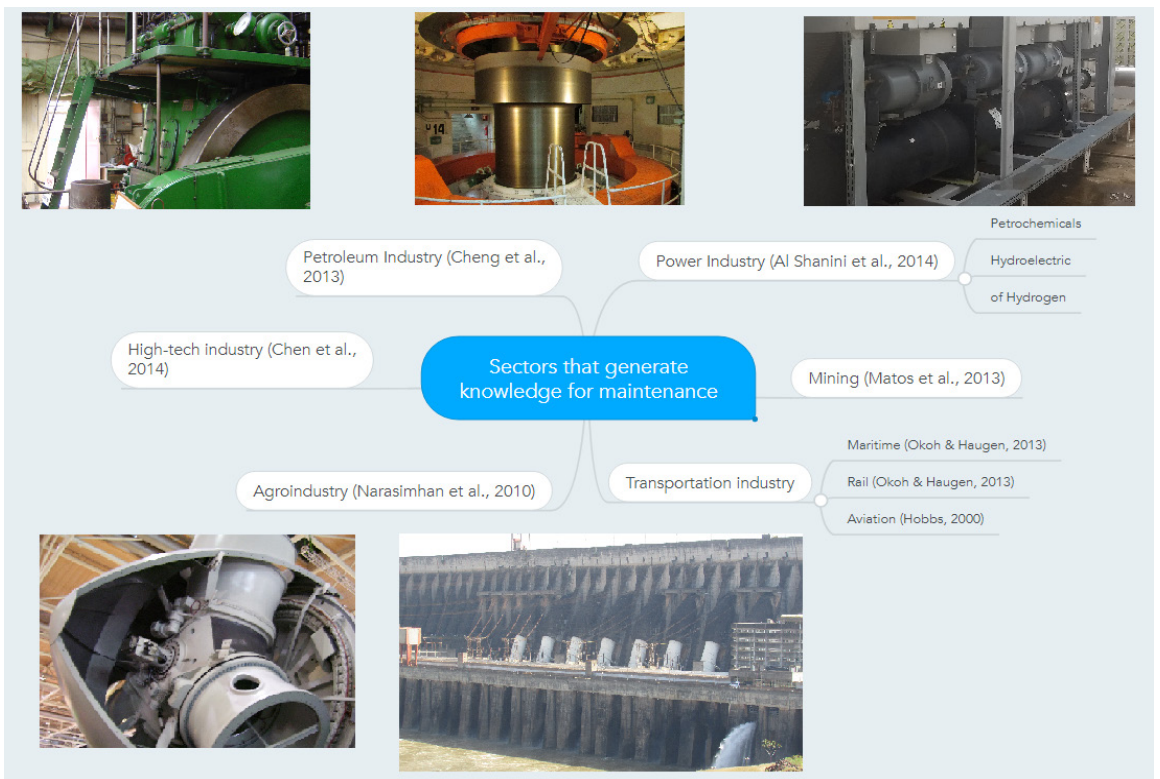

Figure 6. Generation of knowledge in the field of maintenance. Source: developed by the authors. 


\subsubsection{Which phases (design, implementation, review) and types of maintenance (preventive, corrective and predictive) are more prone to suffer influences from OSH?}

With the entry into effect in Brazil of the update of the regulatory standard NR12, which regulates the safety of machinery and equipment (Alves, 2013), organizations are now required to evaluate their safety conditions, emphasizing the operating conditions. Consequently, the greater impact of $\mathrm{OSH}$ on maintenance is linked to the activities of improving and maintaining protection systems and not to the maintenance activity itself.

As with every risk activity, maintenance must also comply with the relevant legislation on workplace safety. However, few articles provided information on these conditions.

For organizations whose activities are inherently risky, such as in the aviation industry, the chemical industry in general and the high-technology industries, the publications emphasize preventive and predictive maintenance strategies because these are directly linked to the safety of their employees and the prevention of accidents with environmental damage. For the same reason, they use assessments of the safety levels to determine the inclusion of improvements, and guidelines for the deployment projects of new structures that have already been adapted to safety standards. These also adopt safety inspections related to the review of maintenance activities (Oliveira \& Siqueira, 2015).

Barbosa (2015) describes that the risk involved with the maintenance department is the operational risk and it is linked to losses or consequences of failures in processes, people or systems. One could also highlight that modern designs involve great technical complexity and require a high diversity of skills, and new forms of management have been developed to deal with this change. Project management is one of them, where risk management is a tool that is still little used in Brazil, which identifies the associated risks still in the design phase (Matos et al., 2013).

Due to the low number of articles associating the types and stages of maintenance with safety, it was not possible to satisfactorily answer the proposed question.

\section{Concluding remarks}

Following the objective of this work, it is concluded that there are fundamental relationships between $\mathrm{OSH}$, Maintenance and Asset Management and that maintenance has a central role to play in these relationships. Due to the risky nature of this activity, $\mathrm{OSH}$ needs to work together in the planning and supervision of working conditions, both for the company and for the maintenance operators.

Both maintenance and occupational health and safety are secondary activities of companies, and both are seen as a necessary cost for proper operations. Asset management, on the other hand, is focused on management practices geared to assets, and its relationship with maintenance is therefore much stronger than safety, which tends to provide a systematization of the activities and the search for solutions.

The contributions to the second question, which sought to identify the impact on maintenance activities in $\mathrm{OSH}$, planning and implementation, included the prioritization of maintenance as a function of safety, the inclusion of activities seeking to improve working conditions and the preparation time for maintenance, which includes activities that ensure the safety of those who are conducting maintenance. 
Another impact would also be the requirement for anyone working on the management of the activities to know about workplace safety since the time of the activities can be changed and even canceled depending on the conditions in which they must be performed.

The third question, which sought to list how the maintenance sector considers the $\mathrm{OSH}$ criteria, can be divided into two situations: first, safety for those performing the maintenance, for example, by evaluating the work conditions, the involvement of production in preventive maintenance activities, such as lubrication; the implementation of services by external staff and its safety implications. Second, where maintenance planning encompasses the company as a whole, working in order to preserve equipment and infrastructure conditions and the maintenance cost evaluations as a function of the risk of equipment failure and the worker safety to determinate the frequency of maintenance on that basis.

The fourth question lists the most impactful branches of activity in the maintenance literature that consider $\mathrm{OSH}$ and in which phases they occur. The transport sector has the most significant impact, with the airline sector having the largest number of articles on the subject, but the transport sector with automotive vehicles, ports, and railways is also represented. Primary industry also had a representative number of articles, especially the petrochemical, mining and high-technology industries. Some articles were found in the energy segment, such as electric power plants, hydroelectric plants and hydrogen plants, which have a preventive approach concerning maintenance and safety.

There were no publications with a similar approach to this work to answer the issues raised in this systematic review of the literature and based on this observation, the grouping of the obtained information was performed. Based on this, it is observed that few articles discuss OSH for the people who perform this maintenance activity.

It is worth noting and proposing for future work that each issue could be an object of study in greater depth and detail, considering the training and levels of difficulty when performing maintenance activities. This study enabled the observation of a large field of research related to maintenance and occupational health and safety, since most articles under study with a focus on maintenance don't make a link with $\mathrm{OSH}$, which is of extreme importance in any activity, especially in this area, which is gaining visibility in companies, which is the maintenance sector.

\section{References}

Al-Shanini, A., Ahmad, A., \& Khan, F. (2014). Accident modelling and safety measure design of a hydrogen station. International Journal of Hydrogen Energy, 39(35), 20362-20370. http://dx.doi.org/10.1016/j.ijhydene.2014.05.044.

Alves, C. A. (2013). Adequação de equipamentos de linha de montagem a norma NR12. In Anais do $28^{\circ}$ Congresso Brasileiro de Manutenção e Gestão de Ativos (pp. 1-13). Rio de Janeiro: ABRAMAN.

Associação Brasileira de Normas Técnicas - ABNT. (2014). NBR ISO 55000 - Gestão de Ativos - Visão geral, princípios e terminologia. Rio de Janeiro: ABNT.

Bamber, C. J., Sharp, J. M., \& Hides, M. T. (1999). Factors affecting successful implementation of total productive maintenance: a UK manufacturing case study perspective. Journal of Quality in Maintenance Engineering, 5(3), 162-181. http://dx.doi.org/10.1108/13552519910282601. 
Barbosa, J. N. (2015). A importância de viabilização da gestão de risco na manutenção. In Anais do $30^{\circ}$ Congresso Brasileiro de Manutenção e Gestão de Ativos (pp. 1-3). Rio de Janeiro: ABRAMAN.

Blaise, J. C., Levrat, E., \& lung, B. (2014). Process approach-based methodology for safe maintenance operation: from concepts to SPRIMI software prototype. Safety Science, 70, 99-113. http://dx.doi.org/10.1016/j.ssci.2014.05.008.

Bourrier, M. (1996). Organizing maintenance work at two American nuclear power plants. Journal of Contingencies and Crisis Management, 4(2), 104-112. http://dx.doi.org/10.1111/j.1468-5973.1996.tb00082.x.

Bristot, V. M., Schaeffer, L., \& Gruber, V. (2012). Manutenção preditiva em indústria de revestimento cerâmicos. Cerâmica Industrial, 17(1), 29-35. http://dx.doi.org/10.4322/cerind.2014.004.

Chen, C. Y., Chang, K. C., Huang, C. H., \& Lu, C. C. (2014). Study of chemical supply system of high-tech process using inherently safer design strategies in Taiwan. Journal of Loss Prevention in the Process Industries, 29, 72-84. http://dx.doi.org/10.1016/j.jp.2014.01.004.

Cheng, C. W., Yao, H. Q., \& Wu, T. C. (2013). Applying data mining techniques to analyze the causes of major occupational accidents in the petrochemical industry. Journal of Loss Prevention in the Process Industries, 26(6), 1269-1278. http://dx.doi.org/10.1016/j.jp.2013.07.002.

Grusenmeyer, C. (2014). Maintenance: organizational modes, activities and health and safety. Use of a French national survey and in-situ analyses. Accident; Analysis and Prevention, 73, 187-199. http://dx.doi.org/10.1016/j.aap.2014.09.009. PMid:25240569.

Herrera, I. A., Nordskag, A. O., Myhre, G., \& Halvorsen, K. (2009). Aviation safety and maintenance under major organizational changes, investigating non-existing accidents. Accident, Analysis and Prevention, 41(6), 1155-1163. http://dx.doi.org/10.1016/j.aap.2008.06.007. PMid:19819363.

Hobbs, A. (2000). Maintenance 'error', lessons from the ATSB survey. Flight Safety Australia, (suppl), 32-39. Retrieved in 2016, April 26, from https://www.atsb.gov.au/media/56951/fsa_0300.pdf

Hobbs, A. (2004). Latent Failures in the hangar: uncovering organizational deficiencies. In Proceedings of the International Society of Air Safety Investigators Annual Seminar (pp. 111). Sterling: ISASI.

Holloway, C. M., \& Johnson, C. W. (2004). Distribution of causes in selected US aviation accident reports between 1996 and 2003 CM holloway. Hampton, Virginia: NASA Langley Research Center.

Hu, J., \& Zhang, L. (2014). Risk based opportunistic maintenance model for complex mechanical systems. Expert Systems with Applications, 41(6), 3105-3115. http://dx.doi.org/10.1016/j.eswa.2013.10.041.

lung, B., Levrat, E., Marquez, A. C., \& Erbe, H. (2009). Conceptual framework for eMaintenance: illustration by e-Maintenance technologies and platforms. Annual Reviews in Control, 33(2), 220-229. http://dx.doi.org/10.1016/j.arcontrol.2009.05.005.

Lafraia, J. R. B. (2011). Liderança para SMS: Compreendendo a infuência da mente na percepção do risco. Rio de Janeiro: Qualitymark Editora Ltda.

Marais, K., Dulac, N., \& Leveson, N. (2004). Beyond normal accidents and high reliability organizations: the need for an alternative approach to safety in complex systems. In Proceedings of the Engineering Systems Division Symposium (pp. 1- 16). Cambridge: Massachusetts Institute of Technology.

Mather, D. (2005). The maintenance scorecard. New York: Industrial Press.

Matos, C., Misael, M. R., Mendes, L. S. D., \& Wohlgemuth, J. M. (2013). O uso da ferramenta de gestão de risco para análise do projeto de controle de contaminação na oficina 
centralizada na Mineração Paragominas - MPSA. In Anais do $28^{\circ}$ Congresso Brasileiro de Manutenção e Gestão de Ativos (pp. 1-13). Rio de Janeiro: ABRAMAN.

Mosquim, J. C. (2015). O homem de manutenção e a absorção de conhecimento. In Anais do $30^{\circ}$ Congresso Brasileiro de Manutenção e Gestão de Ativos (pp. 1- 12). Rio de Janeiro: ABRAMAN.

Murphy, G. D. (2010). Testing a tri-partite contingent model of engineering cultures: a pilot study. Reliability Engineering \& System Safety, 95(10), 1040-1049. http://dx.doi.org/10.1016/j.ress.2010.04.013.

Narasimhan, G. R., Peng, Y., Crowe, T. G., Hagel, L., Dosman, J., \& Pickett, W., Saskatchewan Farm Injury Cohort Team. (2010). Operational safety practices as determinants of machinery-related injury on Saskatchewan farms. Accident, Analysis and Prevention, 42(4), 1226-1231. http://dx.doi.org/10.1016/j.aap.2010.01.016. PMid:20441836.

Okoh, P., \& Haugen, S. (2013). Maintenance-related major accidents: classification of causes and case study. Journal of Loss Prevention in the Process Industries, 26(6), 1060-1070. http://dx.doi.org/10.1016/j.jp.2013.04.002.

Oliveira, E. N. Q., \& Siqueira, A. N. (2015). Viabilidade na implantação do SPIE em um FPSO. In Anais do $30^{\circ}$ Congresso Brasileiro de Manutenção e Gestão de Ativos (pp. 1-13). Rio de Janeiro: ABRAMAN.

Rashid, H. S. J., Place, C. S., \& Braithwaite, G. R. (2014). Erradicating root causes of aviation maintenance errors: introducing the AMMP. Cognition Technology and Work, 16(1), 71-90. http://dx.doi.org/10.1007/s10111-012-0245-4.

Reason, J., \& Hobbs, A. (2003). Managing maintenance error: a practical guide. Hampshire: Ashgate.

Rosqvist, T., Laakso, K., \& Reunanen, M. (2009). Value-driven maintenance planning for a production plant. Reliability Engineering \& System Safety, 94(1), 97-110. http://dx.doi.org/10.1016/j.ress.2007.03.018.

Saedi, A. M., Thambirajah, J. J., \& Pariatamby, A. (2014). A HIRARC model for safety and risk evaluation at a hydroelectric power generation plant. Safety Science, 70, 308-315. http://dx.doi.org/10.1016/j.ssci.2014.05.013.

Santos, J. V., \& Martins, R. A. (2015). Sistema de gestão de risco aplicado a gestão de ativos. In Anais do $30^{\circ}$ Congresso Brasileiro de Manutenção e Gestão de Ativos (pp. 1-16). Rio de Janeiro: ABRAMAN.

Silva, W. L., Nascimento, R. A., Costa, F. P., \& Silva, A. L. (2015). Benefícios da aplicação do método de manutenções preventivas sistêmicas para processos de filtragem em uma empresa do setor de mineração In: Anais do $30^{\circ}$ Congresso Brasileiro de Manutenção e Gestão de Ativos (pp. 1-20). Rio de Janeiro: ABRAMAN.

Weick, K. E., Sutcliffe, K. M., \& Obstfeld, D. (2008). Organizing for high reliability: processes of collective mindfulness - crisis management (Vol. 3, pp. 81-123). London: Sage.

Xavier, J. N. (2013). Manutenção classe mundial. In: Anais do $28^{\circ}$ Congresso Brasileiro de Manutenção e Gestão de Ativos (pp. 1-3). Rio de Janeiro: ABRAMAN.

Xenos, G. H. (2004). Gerenciando a manutenção produtiva. Nova Lima: INDG.

Zhang, H. D., \& Zheng, X.-P. (2012). Characteristics of hazardous chemical accidents in China: a statistical investigation. Journal of Loss Prevention in the Process Industries, 25(4), 686693. http://dx.doi.org/10.1016/j.jp.2012.03.001.

Zhao, Y., Lu, M., \& Yuan, Y. (2000). Operation and maintenance integration to improve safety. Computers \& Chemical Engineering, 24(2-7), 401-407. http://dx.doi.org/10.1016/S00981354(00)00429-4. 